\title{
Setting the benchmark
}

\author{
Thoralf M. Sundt, MD
}

\author{
From the Division of Cardiac Surgery, Massachusetts General Hospital, Boston, Mass \\ Disclosures: Author has nothing to disclose with regard to commercial support. \\ Received for publication Feb 26, 2016; accepted for publication March 1, 2016. \\ Address for reprints: Thoralf M. Sundt, MD, Division of Cardiac Surgery, Massachusetts General Hospital, 55 \\ Fruit Street, Boston, MA 02114 (E-mail: tsundt@mgh.harvard.edu). \\ J Thorac Cardiovasc Surg 2016;151:1339 \\ $0022-5223 / \$ 36.00$ \\ Copyright (c) 2016 by The American Association for Thoracic Surgery \\ http://dx.doi.org/10.1016/j.jtcvs.2016.03.005
}

There are very few true benchmark studies in medicine. This is one.

A benchmark is, according to the Oxford Dictionary, " "a standard point of reference against which things may be compared or assessed." Originally a tool for surveyors, a benchmark provides information regarding latitude, longitude, and altitude above sea level. This 28-year experience with more than 3000 patients undergoing thoracoabdominal aortic aneurysm repair for a spectrum of pathologies and using a variety of adjuncts is one not likely ever to be equaled in magnitude; as such, it provides a valuable reference point in the management of thoracoabdominal aortic aneurysm disease. Furthermore, the extent of the experience provides a unique opportunity to stratify risk factors and outcomes with sufficient granularity to guide us in the appropriate application of novel future therapeutic approaches. For example, better survival was observed among patients with chronic dissection, but worse among those with atherosclerotic aneurisms and comorbidities, such as coronary artery disease, pulmonary disease, and cerebrovascular disease. This suggests that less-invasive even if potentially less "permanent" interventions, such as endovascular approaches, may be more appropriate in the latter than in the former.

Overall, even in expert hands, thoracoabdominal aneurysm repair remains a risky business. With an operative mortality rate of $7.5 \%$ overall, paraplegia or paraparesis occurred in $5.4 \%$ of patients and permanent renal failure occurred in $5.7 \%$ of patients. The risks were highest, as one would expect, among those patients with the most extensive aneurysmal disease. To be fair to the authors, they included all comers, with approximately 200 repairs performed in octogenarians among whom the mortality rate was approximately $20 \%$. Those with rupture had a similar mortality rate. Because the most common application of these data likely will be in decision-making about elective prophylactic repair, it is the mortality rate of only $3 \%$ among patients with Marfan syndrome and 7\% among those with chronic dissection that will be most useful in the clinic.

Perhaps the most dreaded complication of this operation is paraplegia, which occurred in just less than $3 \%$ overall and just more than $1 \%$ among patients aged less than 50 years. Among patients with extent II and III aneurysms, paraplegia occurred in $4.7 \%$ and $4.4 \%$, respectively, although less among

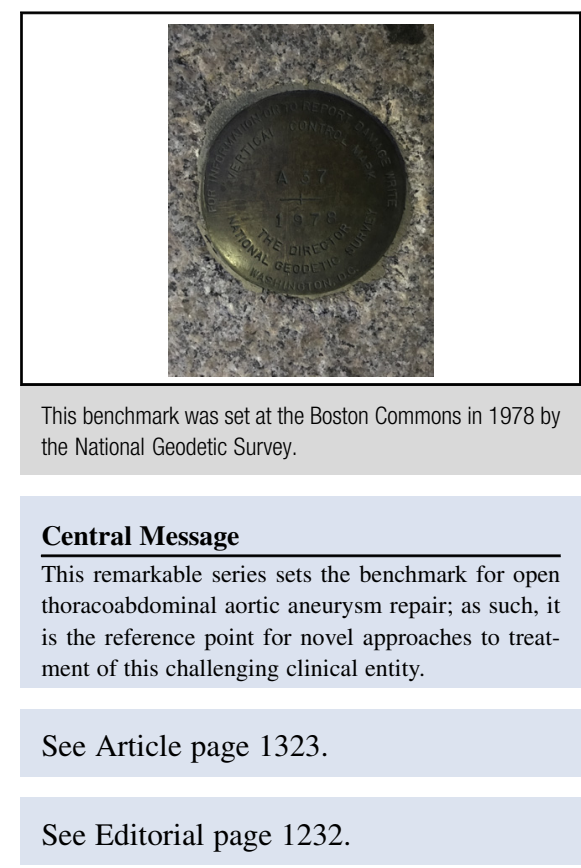

those with genetically triggered origin as opposed to those with atherosclerotic origin. Late survival was superior for patients with chronic dissection, and late failure was uncommon with freedom from repair failure $94 \%$ at 15 years. These results will be of importance to those evaluating the application of stent graft technologies for patients with chronic dissection.

These results stand as a benchmark, a reference point for that which can be accomplished with the technique of moderate systemic heparinization with mild permissive hypothermia, selective reattachment of intercostal vessels, and cold renal artery perfusion in addition to left heart bypass and cerebrospinal fluid drainage. As such, it is a standard against which novel approaches to the treatment of this condition, including endovascular approaches, should be measured. The lack of an "era effect" is sobering and reflects the remarkable challenge presented by these complex patients and complicated procedures. Although the term "benchmark" is commonly used today in business as if to establish the target or goal, in this case we should refer back to the original meaning as a reference point. A benchmark is not a ceiling or floor to the outcomes that can be achieved, but is just a point, like a waymarker, along the journey to improving surgical care. We should take heed of the author's admonition that "there is still room for improvement."

\section{References}

1. Oxford Dictionaries. Definition of benchmark. Available at: http://www oxforddictionaries.com/us/definition/american_english/benchmark?q=Benchmark. Accessed March 15, 2016. 